\title{
CULTURA E ENSINO DE LÍNGUAS NAS DIRETRIZES CURRICULARES NACIONAIS DE LETRAS
}

\section{Lúcia de Fátima Santos}

Resumo: Neste artigo tem-se como objetivo fazer uma análise crítica da(s) visão(ões) de cultura e de ensino de línguas que permeia(m) as Diretrizes Curriculares Nacionais do curso de Letras, com base nas reflexões de autores como Kramsch (1998 e 2000), Thompson (1999), entre outros.

Palavras-chave: cultura; ensino de línguas; Diretrizes Curriculares Nacionais de Letras

Em qualquer análise que seja realizada sobre ensino de um modo geral, é pertinente considerar que questões da micro-realidade da sala de aula refletem uma macro-realidade histórico-social intrinsecamente vinculada a esse contexto. Por isso são imprescindíveis reflexões acerca dos documentos que determinam o trabalho desenvolvido nas escolas em todos os níveis de ensino. Nesse sentido, justifica-se a necessidade de análises críticas, como a de Cavalcante (2002) sobre os Parâmetros Curriculares Nacionais, documento que tem interferido demais nas práticas pedagógicas de todas as séries do ensino fundamental. Já no ensino superior, não é possível desconsiderar as determinações apresentadas nas Diretrizes Curriculares Nacionais que norteiam os cursos de graduação, porque é em função delas que são estabelecidas as coordenadas básicas dơs direcionamentos desses cursos.

Neste artigo, interessa-me particularmente refletir sobre a(s) concepção(ções) de ensino de línguas e de cultura que permeia(m) a constituição das Diretrizes Curriculares do Curso de Letras. O interesse pela discussão desse documento resulta das reflexões que

Artigo apresentado no XIV Intercâmbio de Lingüística Aplicada (abril/2004).

* Doutoranda em Lingüística no PPGLL (Ufal) e professora do Departamento de Letras Clássicas e Vernáculas da Ufal. 
tenho apresentado sobre uma variedade de lacunas existentes na formação dos futuros professores de línguas (LM e LE) nos grupos de pesquisa de que tenho participado nos últimos seis anos ${ }^{1}$. Muitos dos alunos concluintes chegam, por exemplo, ao último ano de Letras sem saber articular as idéias de um texto, como facilmente se comprova nos trabalhos de conclusão de curso. Entre as diferentes razões que justificam fato como esse, acredito que muito se deve à concepção dominante de cultura e ensino de línguas defendida na prática pedagógica desse curso, mesmo depois das grandes e decisivas contribuições de estudos lingüísticos já terem motivado alterações nesse quadro.

Para discutir essa questão, levarei em consideração reflexões propostas por Kramsch (1998 e 2000), Thompson (1995) e Brito (1999) que, mesmo falando de lugares diferentes, comungam da idéia de que entre língua e cultura há uma relação intrínseca. Todos esse autores também defendem o ponto de vista de que é imprescindível considerar língua e cultura de forma atrelada às práticas sociais. Ou como afirma Bakhtin (1997, p. 282), "a língua penetra na vida através dos enunciados concretos que a realizam, e é também através dos enunciados concretos que a vida penetra na língua."

Após alertar sobre a variedade de acepções que existem sobre cultura, Thompsor (1995) apresenta quatro concepções básicas: clássica $^{2}$, descritiva, simbólica e estrutural, enfatizando a defesa dessa última. Nesse sentido, ele frisa que o termo estrutural aqui não deve ser confundido com estruturalista (p.182). Concepção estruturalista de cultura remete a um enfoque das "relações sociais estruturadas nas quais os símbolos e as ações estão inseridos" (p.166). Portanto, não se trata de uma análise dos traços estruturais internos das formas simbólicas, tal como propõe a corrente estruturalista, mas de uma

Atualmente participo do Grupo de Pesquisa Ensino e aprendizagem de línguas, sob a coordenação geral da Profa. Dra Rita Zozzoli.

2 De acordo com Thompson (1995, p. 166), a concepção clássica de cultura é um processo de desenvolvimento intelectual ou espiritual; a concepçāo descritiva é "um variado conjunto de valores, crenças. costumes, convenções, hábitos e práticas características de uma sociedade específica ou de um período histórico"; c a concepção simbólica é a interpretação dos símbolos e das ações simbólicas. 
abordagem dos contextos e processos socialmente estruturados. Nessa perspectiva, ele define uma análise cultural como o estudo das formas simbólicas (ações, objetos e expressões significativas de vários tipos) "em relação a contextos e processos historicamente específicos e socialmente estruturados dentro dos quais, e por meio dos quais, essas formas simbólicas são produzidas, transmitidas e recebidas" (p.181). Nas considerações feitas sobre o aspecto intencional e o caráter constitutivo dessas formas simbólicas, Thompson afirma que elas são expressões das relações entre sujeitos, estabelecidas em processos interlocutivos. Segundo esse autor, "mesmo no caso de um diário, que não é feito para circular, o sujeito-produtor escreve para um sujeito, isto é, para o próprio sujeito que escreve o diário e que possui, com exclusividade, a chave interpretativa" (p.184).

Ao discutir o vínculo entre as características dos contextos sociais e as produções das formas simbólicas, Thompson (op cit, p.20i) afirma que o processo de recepção dessas formas não é passivo, "ao contrário, é um processo criativo de interpretação e avaliação no qual o significado das formas simbólicas é ativamente constituído e reconstituído". Sendo assim, os sujeitos não absorvem passivamente as formas simbólicas, mas de modo ativo e criativo.

É possível associar essas reflexões de Thompson com a visão dialógica de língua proposta por Bakhtin (1992), que, mesmo sem adotar a perspectiva dos estudos culturais, defende a idéia de que a interação verbal constitui a realidade fundamental da língua, por isso "qualquer tipo genuíno de compreensão deve ser ativo, deve já conter o germe de uma resposta" (p.131). Em defesa dessa posição ativa, também cabem reflexões como as de Kramsch ( 2000, p.3 ) de que sujeitos, nos grupos sociais dos quais participam "não expressam apenas experiências; eles também criam experiências por meio da língua. E lhes dão significado através dos meios que escolhem para se comunicar uns com os outros". Esse processo de interação é enfatizado por Kramsch, ao discutir a importância de se colocar no lugar de fronteira, denominado de terceiro lugar, no processo de aprendizagem de uma língua. Segundo essa autora, ao confrontar sua cultura com a cultura do outro, o aprendiz de uma língua situa-se em um lugar de exploração em que é possível ter um maior consciência de sua própria cultura, ao mesmo tempo em que explora a cultura do outro. Ainda, de acordo com Kramsch (1998, p. 234), "não podemos 
ensinar o entendimento do estrangeiro enquanto o familiar não tiver se tornado estrangeiro para nós em muitos aspectos."

Como já sinalizei no segundo parágrafo deste texto, essa visão ativa e produtiva de língua e de cultura apresentada até então não corresponde ao que efetivamente acontece na realidade de ensino de línguas, nos diferentes níveis de ensino. Segundo Brito (1999, p.24), "freqüentemente, o currículo do ensino de línguas estrangeiras sugere uma clara distinção entre o conhecimento lingüístico e o conhecimento cultural, concebendo a aquisição desses aspectos da LE de forma separada". Ainda de acordo com essa autora, o conhecimento cultural "é visto simplesmente como opcional, usado para estimular interesse ou melhorar o conhecimento geral sobre a civilização geral dos falantes da língua alvo." Numa análise em que aborda a questão cultural em relação ao ensino de Português (LM), Bortoni-Ricardo \& Dettoni (2001, p.102) concluem que "a escola precisa tornar-se culturalmente sensível para lidar competentemente com a variação lingüística e cultural de nossas crianças."

Conclusões como a dessas autoras permitem afirmar que ainda prevalece no ensino de línguas a visão de cultura como "um processo de desenvolvimento e enobrecimento das faculdades humanas, um processo facilitado pela assimilação de trabalhos acadêmicos e artísticos ligados ao caráter progressista da era moderna" (Thompson, 1995, p.170), denominada de Cultura MLA, que significa "a grande música, literatura e artes" (Brito, 24). Essa visão elitista de cultura tem uma correspondência com a de ensino de línguas que defende como textos literários apenas os autores considerados clássicos, inclusive são esses autores os referenciais básicos para as atividades de leitura, de produção de textos e, principalmente, para o ensino da gramática. É provável que seja em função dessa visão de cultura que são criados os mitos sobre o ensino de línguas estrangeiras apontados por Moita Lopes (2001).

Essa visão de cultura e de ensino de línguas que propicia um distanciamento com as práticas socioculturais traz sérios prejuízos para os alunos. Como a concepção de língua constitui um dos pilares que norteiam todas as demais concepções envolvidas na prática pedagógica do ensino de línguas, seja a de leitura, de produção de textos ou de gramática, todo o trabalho pedagógico é prejudicado quando se adota uma visão de língua que visa apenas ao ensino de um 
DE LINGGUA ESTRANGEIRA

sistema abstrato de estruturas e regras. Nessa perspectiva, tanto em LM quanto em LE, leitura é vista como a decodificação de um sentido pré-existente no texto; produção como a reprodução de modelos também previstos em geral pelo autor do livro didático; e gramática restringe-se a um conjunto de regras que devem ser seguidas para falar e escrever corretamente.

Em geral, essa concepção de gramática tem constituído a principal razão do ensino de línguas, de modo que os textos lidos ou produzidos são meros pretextos para o ensino de um amontoado de tais regras, que devem ser memorizadas sem questionamento algum. É raríssimo um aluno de $\mathrm{LM}$ ou de $\mathrm{LE}$ que não tenha realizado o preenchimento de lacunas com determinada forma verbal, preposição, conjunção - geralmente indicada entre parênteses- ou não tenha reproduzido o modelo de uma frase, fazendo alterações do tipo singular por plural, masculino por feminino etc.

Opondo-se a essa perspectiva de passividade, Bakhtin (1992, p.124) defende uma concepção de língua que vive e evolui nas interrelações concretas, "não no sistema lingüístico abstrato das formas da língua nem no psiquismo individual dos falantes." Ao fazer menção ao ensino de línguas, ele afirma que o essencial nos métodos de ensino de línguas vivas estrangeiras

é familiarizar o aprendiz com cada forma da língua inserida num contexto e numa situação [...] um método eficaz e correto de ensino prático exige que a forma seja assimilada não no sistema abstrato da língua, isto é, como uma forma sempre idêntica a si mesma, mas na estrutura concreta da enunciação, como um signo flexível e variável.

Ainda falando sobre o ensino de línguas estrangeiras, ele enfatiza a importância de se desenvolver práticas de ensino de línguas em que se privilegie a compreensão, negando, assim, qualquer tipo de orientação que vise apenas ao reconhecimento. Uma diversidade de reflexões que tem sido realizada sobre o ensino da língua materna (LM) me permite afirmar que essas reflexões de Bakhtin (op. cit.) valem também para o ensino de LM, uma vez que é bastante comum encontrar alunos perdidos num emaranhado de regras e 
nomenclaturas, falando da língua materna como se se tratasse de uma língua estrangeira. ${ }^{3}$

\section{Uma leitura das Diretrizes Curriculares de Letras}

A proposta de Diretrizes Curriculares Nacionais do curso de Letras foi publicada em abril de 2001 e teve pequenas alterações em dezembro de 2001, especificamente em relação aos aspectos que devem ser contemplados no projeto pedagógico acadêmico e à determinação da carga horária. É um texto composto pelas seguintes partes: introdução, perfil dos formandos, competências e habilidades, conteúdos curriculares, estruturação do curso e avaliação.

Já no parágrafo inicial fica evidente a visão de ensino e de cultura em que se fundamentam as Diretrizes.Vejamos:

Esta proposta de Diretrizes Curriculares leva em consideração os desafios da educação superior diante das intensas transformações que têm ocorrido na sociedade contemporânea, no mercado de trabalho e nas condições de exercício profissional. Concebe-se a Universidade não apenas como produtora e detentora do conhecimento e do saber, mas, também, como instância voltada para atender às necessidades educativas e tecnológicas da sociedade. Ressalta-se, no entanto, que a Universidade não pode ser vista apenas como instância reflexa da sociedade e do mundo do trabalho. Ela deve ser um espaço de cultura e de imaginação criativa, capaz de intervir na sociedade, transformando-a em termos éticos.

Embora as idéias desse parágrafo apontem para uma possível inter-relação, um diálogo, entre os saberes desenvolvidos na universidade e a realidade sócio-histórica e cultural, há evidências de uma pretensa autonomia da universidade, seja acumulando o duplo papel de "produtora e detentora do conhecimento e do saber," ou de "instância voltada para atender às necessidades educativas e

3 Nesse sentido, vale conferir reflexões que resultaram de análises do grupo de pesquisa já mencionado, como Rosseti, Santos e Zozzoli (2000), Santos ( 1999 ), Zozzoli (1999 e 2003). 
tecnológicas da sociedade". Somado a isso, a universidade deve ser também "um espaço de cultura e de imaginação criativa, capaz de intervir na sociedade, transformando-a em termos éticos." Esse Iugar de poder assumido pela universidade como interventora e transformadora da sociedade se reflete, de algum modo, na concepção dominante de cultura e de ensino de línguas adotada nas práticas pedagógicas, em que, em geral, há uma imposição de conhecimentos desvinculados da realidade sócio-cultural do aluno. Isso permite-me inferir que a cultura de ensino de línguas desenvolvida no contexto universitário favorece mais a opressão do que a autonomia. Isso é facilmente comprovado no cotidiano acadêmico a começar pela ausência de uma ampla discussão da concepção de cultura que se defende. Como afirma Brito (1990, p.45), "cultura" não tem sido debatida na literatura das pedagogias de línguas, mas tem sido inserida nos livros textos e trabalhada superficialmente [...]".

É válido focalizar também nesse parágrafo introdutório das Diretrizes a ressalva de "que a universidade não pode ser vista apenas como instância reflexa da sociedade e do mundo do trabalho." Tal ressalva pressupõe uma negação à concepção de que ensinar uma língua é atender a um princípio utilitarista de expor saberes para atender às necessidades educativas e tecnológicas da sociedade; como também de que aprender uma língua é pôr em uso esses saberes passivamente, assumindo meramente a condição de consumidorreceptáculo, tal como propõe Certeau (1996). Entretanto, a negação a essa visão de ensino de línguas é contraditória com o que é proposto em outros trechos das Diretrizes, como veremos mais adiante ao focalizarmos o perfil do formando de Letras.

Após o parágrafo introdutório, são mencionados os benefícios oferecidos pelo curso em função de suas estruturas flexíveis. Essa flexibilidade também é ressaltada em relação ao currículo, para que assim possa "responder às novas demandas sociais e aos princípios expostos", exigindo que o professor assuma o papel de orientador, "que deverá responder não só pelo ensino de conteúdos programáticos, mas também pela qualidade da formação do aluno." É muito provável que essa insistência em se mencionar flexibilização tenha como objetivo negar uma concepção de cultura e ensino de línguas presa a cânones estabelecidos em toda a história do ensino de línguas. Entretanto, avaliando o teor do texto de um modo geral, 
entendemos essas flexibilidades como propostas de renovações superficiais. Isso se confirma, por exemplo, na observação apresentada logo após se definir atividade acadêmica curricular:

atividade acadêmica curricular - aquela considerada relevante para que o estudante adquira competências $e$ habilidades necessárias a sua formação e que possa ser avaliada interna e externamente como processo contínuo e transformador, conceito que não exclui as disciplinas convencionais ${ }^{4}$.

Esse conceito sugere duas questões: o que se denomina como disciplinas convencionais? Se disciplinas convencionais remetem a uma ordem pré-estabelecida, a manutenção de uma convenção, como conciliar a permanência dessas disciplinas convencionais com o desenvolvimento de um "processo contínuo e transformador"? Essa ênfase para a permanência das disciplinas convencionais parece-me confirmar a idéia de um ensino de línguas centrado em disciplinas que são ministradas de forma segmentada, como acontece, por exemplo, com as disciplinas Redação e Gramática, no ensino médio, e com as disciplinas Fonologia do Português, Morfologia do Português e Sintaxe do Português, no ensino de graduação em Letras. O mais sério é que no desenvolvimento de disciplinas como essas, o ensino da gramática ocupa frequientemente o lugar de maior relevância, ou como afirma Ferreira (2001, p.238), "tudo se passa como se, diante da gramática, não houvesse território mais seguro do que o recurso aos procedimentos consagrados e garantidos pela tradição." Essa resistência à permanência das disciplinas convencionais é antagônica com o perfil que as Diretrizes idealizam para o formando de Letras, conforme está expresso no trecho:

O objetivo do Curso de Letras é formar profissionais interculturalmente competentes, capazes de lidar, de forma crítica, com as linguagens, especialmente a verbal, nos contextos oral e escrito, e conscientes de sua inserção na sociedade e das relações com o outro.

4 Grifo do texto das Diretrizes. 
Independentemente da modalidade escolhida, o profissional em Letras deve ter domínio do uso da língua ou das línguas que sejam objeto de seus estudos, em termos de sua estrutura, funcionamento e manifestações culturais, além de ter consciência das variedades linguíísticas e culturais. Deve ser capaz de refletir teoricamente sobre a linguagem, de fazer uso de novas tecnologias e de compreender sua formação profissional como processo contínuo, autônomo e permanente. A pesquisa e a extensão, além do ensino, devem articularse neste processo. O profissional deve, ainda, ter capacidade de reflexão crítica sobre temas e questões relativas aos conhecimentos linguísticos e literários.

Nesse perfil, vale chamar a atenção para a ampla formação dos formandos, o que dificilmente corresponde à realidade das instituições de ensino, quer essas instituições sejam públicas ou particulares. Observemos nesse perfil a responsabilidade que é atribuída ao futuro profissional em Letras. É interessante notar que na construção inicial do primeiro parágrafo essa responsabilidade é atribuída ao curso de Letras ("O objetivo do curso de Letras é formar..), já no parágrafo seguinte toda a responsabilidade passa a ser do formando ("O profissional em Letras deve ..."). Do ponto de vista ideológico, essa hipotética onipotência atribuída ao aluno corresponde a dizer que, se o aluno termina o curso sem atender a esse perfil, a culpa é dele que não levou a sério o curso, que não estudou nem se dedicou suficientemente, enfim, que é incapaz de se tornar um profissional "interculturalmente competente, crítico, reflexivo e consciente." Quando, na verdade, ele está preso num emaranhado de coerções de habilidades e competências, assumindo a posição de receptor passivo.

A idealização do perfil do formando é reenfatizada na descrição das competências e habilidades, como se verifica em:

$O$ graduado em Letras, tanto em língua materna quanto em língua estrangeira clássica ou moderna, nas modalidades de bacharelado e de licenciatura, deverá

5 O gripo nas formas do verbo dever é nosso. 
ser identificado por múltiplas competências e habilidades adquiridas durante sua formação acadêmica convencional, teórica e prática, ou fora dela.

Nesse sentido, visando à formação de profissionais que demandem o domínio da língua estudada e suas culturas para atuar como professores, pesquisadores, críticos literários, tradutores, intérpretes, revisores de textos, roteiristas, secretários, assessores culturais, entre outras atividades, o curso de Letras deve contribuir para o desenvolvimento das seguintes competências $e$ habilidades:

- domínio do uso da língua portuguesa ou de uma língua estrangeira, nas suas manifestações oral $e$ escrita, em termos de recepção e produção de textos;

- reflexão analítica e crítica sobre a linguagem como fenômeno psicológico, educacional, social, histórico, cultural, político e ideológico;

- visão crítica das perspectivas teóricas adotadas nas investigações lingüisticas e literárias, que fundamentam sua formação profissional;

- preparação profissional atualizada, de acordo com a dinâmica do mercado de trabalho;

- percepção de diferentes contextos interculturais;

- utilização dos recursos da informática;

- domínio dos conteúdos básicos que são objeto dos processos de ensino e aprendizagem no ensino fundamental e médio;

- domínio dos métodos e técnicas pedagógicas que permitam a transposição dos conhecimentos para os diferentes níveis de ensino.

O resultado do processo de aprendizagem deverá ser a formação de profissional que, além da base específica consolidada, esteja apto a atuar, interdisciplinarmente, em áreas afins. Deverá ter, também, a capacidade de resolver problemas, tomar decisões, trabalhar em equipe e comunicar-se dentro da multidisciplinaridade dos diversos saberes que compõem a formação universitária em Letras. O profissional de Letras deverá, ainda, estar 
compromissado com a ética, com a responsabilidade social e educacional, e com as consequiências de sua atuação no mundo do trabalho. Finalmente, deverá ampliar o senso crítico necessário para compreender a importância da busca permanente da educação continuada e do desenvolvimento profissional.

A presença da modalização de ordem, expressa repetidas vezes com o verbo dever, é intensificada nesse trecho quando são apresentadas as competências e habilidades. Talvez porque aqui seja dito ao aluno, em tom enfático, que se espera dele uma mega formação, para a qual o curso "deve contribuir", mas cabe a ele se esforçar para ser um profissional com o domínio de oito competências e habilidades. Gostaria de chamar a atenção para a forma categórica como são apresentadas essas competências e habilidades. Veja, por exemplo, que quando se trata de ter domínio, tem que ser total, seja "do uso da língua portuguesa ou de uma língua estrangeira [...] nas suas modalidades oral e escrita", ou dos conteúdos básicos do ensino fundamental e médio, ou dos métodos e técnicas pedagógicas.

Ainda nesse trecho das habilidades, vale salientar a afirmação de que "o resultado do processo de aprendizagem deverá ser a formação de profissional que, além da base específica consolidada, esteja apto a atuar, interdisciplinarmente, em áreas afins". Essa proposta de atuação interdisciplinar é paradoxal com o que se propôs anteriormente no texto a respeito da permanência das disciplinas convencionais. Evidentemente, estou estabelecendo o paradoxo a partir das reflexões levantadas por aqueles que fazem, de fato, Lingüística Aplicada ${ }^{6}$, não aplicação da Lingüística.

Retomando a questão da permanência das disciplinas convencionais juntamente com a questão de a universidade ser "produtora e detentora do conhecimento e do saber,"é possível afirmar que há uma contradição no trecho a seguir quando se propõe a visão de língua como prática social e defende-se o objetivo de "dar prioridade à abordagem intercultural".

Sobre a relação entre Lingüística Aplicada e aplicação da Lingüística vale conferir reflexões como as de Cavalcante \& Moita Lopes (1991) e Signorini \& Cavalcante (1998). 
Considerando os diversos profissionais que o curso de Letras pode formar, os conteúdos caracterizadores básicos devem estar ligados à área dos Estudos Lingüísticos e Literários, contemplando o desenvolvimento de competências e habilidades específicas. Os estudos linguiísticos e literários devem fundar-se na percepção da língua e da literatura como prática social e como forma mais elaborada das manifestações culturais. Devem articular a reflexão teórico-crítica com os domínios da prática - essenciais aos profissionais de Letras, de modo a dar prioridade à abordagem intercultural, que concebe a diferença como valor antropológico e como forma de desenvolver o espírito crítico frente à realidade.

Como é possível conciliar a visão de linguagem como prática social com a predeterminação de habilidades e competências que devem ser adotadas passivamente pelos sujeitos? É possível se ter como propósito o desenvolvimento do espírito crítico frente à realidade quando essa realidade é idealizada?

Na discussão sobre a estruturação do curso, por ser o único momento do texto das Diretrizes em que há uma certa abertura, talvez haja espaço para se refletir sobre essas questões ao se elaborar o projeto pedagógico. No momento dessa elaboração, quando se espera que sejam discutidas as Diretrizes Curriculares, é possível que os sujeitos envolvidos fiquem atentos às maneiras de consumir os produtos (ideológicos) impostos por essas Diretrizes, encontrando formas de fazer diferente da ordem dominante.

A última parte das Diretrizes diz respeito às determinações a serem seguidas no sistema de avaliação que deve ser implementado pelo colegiado do curso. Nesse item são apontados cinco aspectos em que deve pautar-se esse sistema de avaliação: a coerência das atividades quanto à concepção e aos objetivos do projeto pedagógico e quanto ao perfil do profissional formado pelo curso de Letras; a validação das atividades acadêmicas por colegiados competentes; a orientação acadêmica individualizada; a adoção de instrumentos variados de avaliação interna; a disposição permanente de participar de avaliação extema. 
DE LÍNGUA ESTRANGEIRA

É interessante notar que, embora o quinto aspecto faça menção à disposição de se participar de avaliação externa, não há referência alguma ao Provão. Talvez porque esse exame seja em parte uma negação do perfil idealizado por essas Diretrizes, embora alguns dos princípios adotados sejam semelhantes, como a visão homogeinizante de ensino, a concepção de cultura e de língua desvinculada da realidade, a ênfase sobre o domínio de conteúdos, entre outros.

\section{Inquietações finais}

Após a leitura desse documento, quaisquer considerações finais têm conotação de inquietações, porque as tentativas de renovação no ensino de línguas propostas são, de um modo geral, ou repetidas formas sob outro enfoque ou novas formas ainda muito distantes da realidade cotidiana dos cursos de Letras. Há trechos, como o do perfil dos formandos, cujas determinações são muito difíceis de ser cumpridas, não por incapacidade dos alunos e/ou dos professores, mas por uma série de implicações de ordens diversas no processo de formação, que não se resolvem com o engessamento de habilidades e competências.

Qualquer profissional que atue de modo reflexivo nos cursos de Letras reconhece que alguns pontos apresentados nesse documento não correspondem à caracterização de um professor que se deseja para mudar o quadro do ensino de línguas que se encontra facilmente nos diferentes contextos educacionais. Reconhece também que a precariedade da formação dos profissionais de Letras não se resolve com ações construídas sem vínculo algum com a realidade de ensino. mas a partir de uma reflexão séria, criteriosa e responsável de cada contexto educacional e da criação de um projeto político-pedagógico que, de fato, corresponda às necessidades dos sujeitos envolvidos. Isso implica, entre outros aspectos, a formulação de Diretrizes que partam? de resultados de um amplo diálogo com professores e alunos comprometidos com as orientações (não determinações) a serem formuladas, de modo que tais sujeitos se sintam co-responsáveis pelo que será proposto, assumindo assim o compromisso de pôr em prática ações executáveis e reais. Somente assim é possível apostar em umi abordagem intercultural no ensino de línguas, vislumbrando il conquista da bandeira do terceiro lugar de que fala Kramsch (1993), a 
efetivação de práticas dialógicas, tal como propõe Bakhtin (1992, 1997), e um ensino de línguas em que professores e alunos problematizem questões e proponham alternativas possíveis, buscando ultrapassar as limitações do contexto cultural em que estão inseridos.

\section{Referências}

BAKHTIN, M. Marxismo e filosofia da linguagem. São Paulo: Hucitec, 1992.

BAKHTIN, M. Estética da criaçāo verbal. São Paulo: Martins Fontes, 1997.

BRITO, I..A de. Conceitos de cultura e competência: contribuições para um ensino crítico de inglês no contexto brasileiro. Dissertação de Mestrado. Instituto de Estudos da Linguagem. Campinas: Unicamp, 1999.

CAVAlCANTI, Marilda C. \& MOITA LOPES, Luiz Paulo. Implementação de pesquisas na sala de aula de línguas no contexto brasileiro. Trabalhos em Lingüística Aplicada. Campinas, $n^{\circ} 17$, p.133-144, 1991.

CAVAlCANTE, Maria do Socorro Aguiar de Oliveira. Ensino de qualidade e cidadania nos PCN: o simulacro de um discurso modernizador. Tese de Doutorado. Programa de Pós-Graduação em Letras da Ufal, 2002. (Inédita)

CERTEAU, Michel. A invenção do cotidiano: artes de fazer. Petrópolis: Vozes, 1996.

FERREIRA, Herbert Luiz B. Gramática e aquisição: a relação ente o foco na forma e a aquisição de língua estrangeira em situação institucional. Dissertação de Mestrado. Instituto de Estudos da Linguagem. Campinas: Unicamp, 2001.

KRAMSCH, Claire. The relationship of language and culture. In Context and culture in language teaching. Oxford: University Press, 2000 , p. 3-14.

KRAMSCH, Claire. Looking for third places in Language and culture. Oxford: University Press, 1998, p. 233-259. 
ROSSETI, Márcia; SANTOS, Lúcia de Fátima; ZOZZOLI, Rita. The search for autonomy: a challenge the student reader. Revista Ilha do Desterro, Florianópolis: UFSC, 2000.

SANTOS, Lúcia de Fátima. Gramática, leitura e produção: articulação desafiadora e necessária no ensino de língua materna. In: MOURA, Maria Denilda (Org.) Múltiplos usos da língua. Maceió: Edufal, 1999, p. 132-4.

SIGNORINI, Inês \& CAVALCANTI, Marilda (Org.). Linguïística aplicada e transdisciplinaridade: questōes e perspectivas. Campinas: Mercado de Letras, 1998.

THOMPSON, John B. O conceito de cultura. In Ideologia e cultura moderna: teoria social crítica na era dos meios de comunicação de inassa. 5. ed.. Petrópolis, 1995.

ZOZZOLI, Rita. O processo de constituição de uma gramática do aluno leitorl produtor de textos: a busca de autonomia. In: Revista Trabalhos em LA. Campinas: Unicamp, v. 33, 1999.

ZOZZOLI, Rita. Atividades de reflexão gramatical na sala de aula e autonomia relativa do sujeito. In: A interação na aprendizagem das línguas. Pelotas: EDUCAT, 2003. 